\title{
Glückwünsche des Rektors anlässlich des 75. Geburtstages von Em.O.Univ.-Prof. Dipl.-Ing. Dr. mont. Hans Jörg Steiner
}

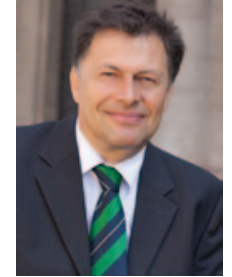

Im Rahmen der akademischen Feier zu Ostern 2012 war es mir eine Ehre und Freude, Herrn Em.O.Univ.-Prof. Dipl.-Ing. Dr. mont. Hans Jörg Steiner das goldene Doktoratsdiplom zu überreichen. Hans Jörg Steiner leitete die Geschicke des Institutes für Aufbereitung und Veredlung an der Montanuniversität Leoben in den Jahren 1968 bis 2005, also über den beachtlichen Zeitraum von 37 Jahren. Ich habe ihn in den gemeinsamen Jahren an der Montanuniversität im Zuge des gemeinschaftlichen Zusammenarbeitens als eine Persönlichkeit kennen und schätzen gelernt, die sich durch ihre Offenheit und Geradlinigkeit ausgezeichnet hat. Mit seinen Arbeiten auf dem Gebiet der Aufbereitungstechnik hat er sich einen Ruf als hoch geschätzter akademischer Lehrer und Forscher weit über die Grenzen des Landes hinaus erworben. Sein Arbeitsgebiet, das durch die immer deutlicher werdende Rohstoffverknappung ste- tig an Bedeutung gewinnt, wurde Hans Jörg Steiner offensichtlich in die Wiege gelegt. Er wurde 1937 in Eisenerz/ Steiermark als Sohn einer dem Bergbau seit mehreren Generationen verbundenen Familie geboren.

Die Montanuniversität Leoben ist Hans Jörg Steiner zu großem Dank verpflichtet. Dank für die vielen Jahre, in denen er sich der Ausbildung von Generationen an Bergund Gesteinshüttenleuten widmete, in denen er mit tiefem Verständnis für die physikalischen Gesetzmäßigkeiten seine stets anwendungsorientierten Forschungsschwerpunkte konsequent vorantrieb und in denen er sich in eine Reihe bedeutender Kommissionen am gedeihlichen Fortbestand unserer Alma Mater einbrachte.

Im Namen der Montanuniversität Leoben und natürlich auch in meinem Namen erlaube ich mir, Herrn Em.O.Univ.Prof. Dipl.-Ing. Dr. mont. Hans Jörg Steiner das Beste für seinen weiteren Lebensweg, insbesondere Gesundheit, Glück und Zufriedenheit, zu wünschen.

Mit einem herzlichen Glückauf,

Univ.-Prof. Dipl.-Ing. Dr. techn. Wilfried Eichlseder Rektor der Montanuniversität Leoben wilfried.eichlseder@unileoben.ac.at 